\title{
Technology Acceptance Model for the Use of M-Health Services among health related users in UAE
}

\author{
Mohamed Alloghani, Abir Hussain, Dhiya Al-Jumeily, Omar Abuelma'atti \\ School of Computing and Mathematical Sciences \\ Liverpool John Moores University \\ Liverpool, Merseyside, UK \\ \{M.AlLawghani, A.Hussain, D.Aljumeily, O.E.Abuelmaatti\}@1jmu.ac.uk
}

\begin{abstract}
This paper aims to identify the main factors that influence health related users' acceptance to mobile health services technology as a mean for receiving general health services. This study proposes Technology Acceptance Model (TAM) modified by incorporating external variables including perceived security and perceived trust in order to determine the factors that mostly influence the intention to use M-Health services. In this study, the proposed research model and hypotheses tested and validated with a data collected from the survey questionnaires distributed to a sample of 144 Emiratis and Non-Emiratis patients, general health users and health professional. In our research, we apply the frequency analysis, descriptive analysis, correlation test, t-test, Reliability \& convergence and discriminant validity. The research made an in-depth examination of the variables that influence the intention to use $M$ Health services by focusing on main stakeholders including patients, visitors and health professionals. The proposed research model is applicable as per the results achieved from the survey and it can be applied to evaluate M-Health users' acceptance and help government and non-government entities to develop $m$-health services that align with the needs of the users.
\end{abstract}

Keywords-e-Health, M-Health, SPSS, Apps, KIOSK, IVR

\section{INTRODUCTION}

With the rapid growth and evolution of the internet that led to the development of useful tools for mobile technology. As a result, Mobile health (M-Health) technologies considered powerful solution that covers among other technologies important traits such as management of patients' records monitor the status of patients in innovative way, measure the blood pressure, heart rate and body temperature.

M-Health covers medical and health practices supported by different mobility platforms including mobile phones, wireless devices and monitoring devices [1].

In comparison, electronic health (e-health) is the conventional way of delivering healthcare services that rely on desktop computers and wired connectivity. M-Health has emerged as an extended component of e-Health; however, it does not replace it [2]. It is another way of delivering health services using a new innovative communication channel that aims to connect patients with their doctors, providing access to data, lowering treatment costs, increasing efficiencies and facilitating remote health care. The mHealth service includes applications (Apps) like health information systems, vaccinations schedules, appointment and medication reminders. These Apps helps people to reshape their lifestyle and develop good behaviors, as they are portable, flexible and accessible to healthcare services [3].

The benefits of mobile devices and mHealth are noticeable in the developing countries. This advancement has led to current mobile apps, remote health and care monitoring, patients' tracking, medical treatment being transformed from the conventional way to cutting-edge approaches. Great potentials for healthcare can be witnessed such as increased quality of life, sustainable healthcare; more empowered patients who may play participative role while enhancing their responsibility over their health thru mobile apps that motivates them to adhere to medication, treatment and scheduled observations appointments [4].

\section{LITERATUREREVIEW}

There are several theories that have emerged to describe and explain possible factors that affects individuals' acceptance/ rejection/ continuity to use or adopt new technologies. Some of the theories that have been widely used to describe the Technology Acceptance, namely:

- Technology Acceptance Model [5].

- Technology Acceptance Model 2 [8].

- Combined TAM and TPB (C-TAM-TPB) [9].

- Theory of Reasoned Action (TRA) [19].

- Theory of Planned Behavior (TPB) [20].

- Decomposed Theory of Planned Behavior (DTPB) [23].

Technology Acceptance Model (TAM) first was developed by Fred Davis in 1989 as a theory of information system that models how users understand, approach, utilize, come to accept and use a technology. It has been widely used as conceptual model in predicting adoption behavior of information technology [5]. TAM was developed from TRA and used as basis for specifying linkage between key beliefs: Perceived ease of use, Perceived Usefulness (PU), intention to use, users' attitudes and computer usage behavior [6]. 
TAM is the most significant extension of Theory of Reasoned Action (TRA) [7]. Furthermore, many interested researchers have expanded TAM many times, as it had some restrictions in providing factors that lead individuals to perceive a given system useful. The subsequent model of TAM was developed by [8] where TAM2 incorporated cognitive and social influences to predict the acceptance of technology. The cognitive aspect included perceived ease of use (PEOU), job relevance, quality's outputs and results demonstrability. While social influences focused mainly on subjective norms and voluntariness [8]. The Theory of Planned Behavior (TPB) originally evolved from the TRA with an added variable perceived behavior control (PCB) [9]. This theory was developed by [10] that encouraged many researchers to consider the prediction of people's behavior towards the use of technology [11]. Three identified features of TPB mainly focused on investigating beliefs related to each situation, beliefs that may generalize to other situations and other beliefs that may not [12]. The combined TAM and TPB (C-TAMTPB) developed by [23] as a hybrid model integrated to include perceived behavioral control and subjective norms into the TAM demonstrated thru empirical study that revealed results of high corresponding in describing the behaviors of users on using new technology [13]. The Decomposed Theory of Planned Behavior (DTPB) was developed by [23] with the aims on explaining the users' behaviors based on the relationship between intention, attitude, behavior and beliefs. This DTPB focuses on identifying the beliefs and variables that affect the behavior's aspects namely, subjective norms, attitudes and perceived behavioral control [9]. Based on the literature review, we proposed the research model and hypotheses (Figure 1) for investigation.

\section{RESEARCH MODEL AND HYPOTHESES}

The research model of this study is to explore the factors that affect the adoption and actual use of mHealth services among publics in UAE. For the purpose of this research, the main elements of the technology acceptance model incorporated for the development of the proposed hypotheses include the Perceived Usefulness (PU), Perceived Ease of Use (PEOU), Perceived Security (PS) and Perceived Trust (PT).

\section{A) PERCEIVEDUSEFULNESS (PU)}

Several studies [3], [6], [13] and [14] suggested that perceived usefulness as one of the primary factors that predicts the usage of information technology. The Perceived Usefulness first defined by [6], as "The degree to which a person believes that using a particular system would enhance his or her job performance". In the perspective of mHealth, we define the perceived usefulness as the degree to which a person considers that using mobility devices for the services of healthcare will be advantageous to him/her. In other words, if patients and doctors feel that mHealth services are useful and will improve their life, enhance their work performance and assist them to increase their productivity, hence this usefulness will encourage to the intention to use. Based on the above, we hypothesize:
H1: Perceived Usefulness has a strong significant effect on the intention to use mHealth services.

\section{B) PERCEIVED EASE OF USE (PEOU)}

This construct is identified as a major element that stimulate users to use a particular technology. The PEOU defined by [6] as "the degree to which a person believes that using a system would be free of effort". The complexity of ICT systems will influence the ease of use.

When users perceive a particular system as ease of use and help them to complete their tasks and activities, they feel using a system is comfortable and convenient to them, then they will have the desire to use that system accordingly. In these days, patients and health professionals often use mobile phones in their daily activities and this reflects their intention towards the usage of mHealth systems. Thus, we propose:

H2: Perceived Ease of Use has a positive effect on the intention to use mHealth services.

\section{C) PERCEIVEDTRUST}

The authors in [15] suggested that previous experiences have the significant effect on the current level of users' trust. In addition, authors in [16] indicated that trust is a social factor that has major influence on the users of mobile commerce technology. Other study in [17] founds that trust as significant variable affecting both perceived ease of use and perceived usefulness. In some developing countries, heath services provided by government do not perceive acceptable level of trust by the patients. Therefore, we assume that:

H3: Perceived Trust has an effect on the intention to use mHealth services.

\section{D) PERCEIVED SECURITY}

The main aim of accepting mobile health services includes not only improving the quality of patients' life, but also acquiring security and privacy. Several studies reported that security concerns to be a major barrier to the online transactions [18]. Security refers to the protection of a system from internal and external threats, outflow or illegal intrusion, theft and destruction [19]. These concerns have been extended to online transactions and electronic health while technology itself incorporated some security control measures. The M-Health security concerns require other security mechanisms and mitigation approaches instead of relying on the technological resolutions alone. The deployment of health services thru the mobile devices raises some other issues namely, loss of control, data security, data encryption, distribution of information and privacy. 
Based on the above discussion, we propose:

H4: Perceived Security has an effect on the intention to use M-Health services.

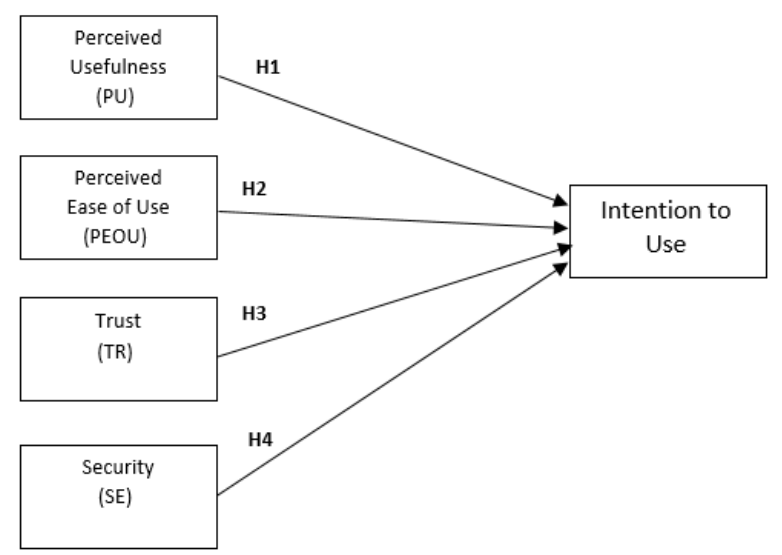

Figure 1: Proposed Research Model

The theoretical model presented in Figure 1, includes the main dependent variable that is intention to use (IU) and independent variables of the attitude toward behavior including the perceived usefulness and perceived ease of use along with incorporated external variables such as trust and security. The selection of the external variables based on the literature and recent trends on the field of $m$-health.

\section{RESEARCHMETHODOLOGY}

The research method used in this study is the mixed methods approach that combines quantitative thru survey questionnaire and qualitative using the Semi-Structured interviews methods. This approach helped us to collect responses from all completed questions within a short period. The survey also helped us to easy administer, cross check the values and relationships between the variables. The qualitative data helped to build on first method in sequence while assisting in explaining and elaborating on quantitative results.

\section{SURVEY ADMINISTRATION}

The proposed hypotheses ( $\mathrm{H} 1, \mathrm{H} 2, \mathrm{H} 3$ and $\mathrm{H} 4)$ of this research model were tested using a survey questionnaire, including questions emphasized on measuring the factors in the represented model. The respondents were patients, health professional and publics from different government and nongovernment hospitals and clinics constitute a sample size of 144. All the participants were comfortable with the use of the online questionnaire and we arranged with the specified hospitals to assist us in providing and using the available computers' facility rooms to meet some participants for the purpose of this project. Doctors provided us with ultimate support by circulating the questionnaires to other private clinics. The data were collected thru a distributed online survey questionnaire and included some general information such as the demographic characteristics of participants and scales, which measure the variables in the proposed research study.

\subsection{MEASUREMENT DEVELOPMENT \& DATA ANALYSIS}

We developed the measurement items in this study based on several discussions, communications and meetings with some experts in the ICT and Mobile applications field along with the literature review in order to maintain the validity and consistency of this study.

The variables in the proposed model were measured using 5-likert scale from one (Strongly Disagree) to five (Strongly Agree) to evaluate the responses from the participants. The content validity was verified thru a pilot test on the measurement items. To ensure the clarity of the measured items, the questionnaire was tested with twenty respondents chosen randomly for the pilot test and results obtained from the questionnaire were modified according to some difficulty that we observed during the Pre-Pilot test and therefore changes have been introduced accordingly. The survey was administered and conducted in the UAE in which we distributed flyers and brochures to health professionals, patients and publics to ensure proper understanding and realization of the mobile health services that Ministry of health $(\mathrm{MOH})$ is offering thru the mobile. The brochures contained some information about services such as vaccinations appointment, treatment schedules, follow-ups, dental appointments and general enquiries about clinics' working hours. The distributed brochures helped to explain the MOH's mobile health services as most of the health professionals had the lowest ICT maturity levels and limited knowledge on using mobile devices and accessing the health services.

Table 1 Demographic profile of survey respondents

\begin{tabular}{|l|c|c|}
\hline \multicolumn{1}{|c|}{ Variables } & Characteristics & $\%$ \\
\hline \multirow{2}{*}{ Gender } & Male & $42.36 \%$ \\
& Female & $57.64 \%$ \\
\hline \multirow{3}{*}{ Age } & 18 to 25 & $11.11 \%$ \\
& 26 to 30 & $18.06 \%$ \\
& 31 to 35 & $25.69 \%$ \\
& 36 to 40 & $15.97 \%$ \\
& 41 to 45 & $9.72 \%$ \\
& 46 to 50 & $11.81 \%$ \\
Qualification & Above 51 & $7.64 \%$ \\
\hline \multirow{2}{*}{ Nationality } & Primary & $2.08 \%$ \\
& Secondary & $14.58 \%$ \\
& Undergraduate & $45.83 \%$ \\
& Post-graduate & $37.50 \%$ \\
\hline & Emirati & $75.00 \%$ \\
\hline & Non-Emirati & $25.00 \%$
\end{tabular}




\begin{tabular}{|l|c|c|}
\hline \multirow{4}{*}{$\begin{array}{l}\text { Preference of } \\
\text { Respondents }\end{array}$} & Websites & \\
\cline { 2 - 3 } & Mobile Services & $71.53 \%$ \\
\cline { 2 - 3 } & Interactive Voice Response (IVR) & $2.78 \%$ \\
\cline { 2 - 3 } & KIOSKS & $3.47 \%$ \\
\cline { 2 - 3 } & SMS & $7.64 \%$ \\
\cline { 2 - 3 } & Service centers & $5.56 \%$ \\
\hline \multirow{3}{*}{ Smart Devices use } & Smart phone & $93.01 \%$ \\
\cline { 2 - 3 } & Non Smart phone & $6.99 \%$ \\
\hline
\end{tabular}

Table 1 illustrates the respondents' demographics where the percentage of gender participated in the conducted survey was male $42.36 \%$ and female $57.64 \%$. Around $25.69 \%$ of the respondents, aged 31 to 35 scored the maximum responses amongst the rest while the minimum responses received $7.64 \%$ aged above 51. The highest qualification of respondents was undergraduate by $45.83 \%$, followed by postgraduates $37.50 \%$ then holders of the secondary certificate by $14.58 \%$ while the lowest was from respondents with primary qualification of $2.08 \%$. The percentage of the nationalities participated in the survey was $75 \%$ from Emiratis and $25 \%$ from the NonEmiratis. Noticeably, $71.53 \%$ of the respondents preferred using the mobile services as favorite channel of receiving health services compared to the rest of channels, while the rest preferred websites with $9.03 \%$ followed by SMS 7.64\%, 5.56\% of respondents preferred to receive health services through MOH's services centers, 3.47\% selected KIOSK (Stand-Alone structure that displays information to users and acts as selfservice structure) [22], while $2.78 \%$ preferred interactive voice response [21]. Collectively, 93.01\% of the respondents are heavily using smart phone devices to receive health services whereas $6.99 \%$ indicate low usage of smart phone devices amongst respondents.

Table 2 shows the independent sample t-test that we used to find the difference in four of the variables with male and female. Here the p-value is greater than the significance level 0.05 for four of them; hence, we can conclude that there is no significant difference on these four factors based on the gender, and both male and female have similar opinion in considering these technologies.

Table 2. T-test for significance of Correlation

\begin{tabular}{|c|c|c|c|c|c|c|}
\hline Items & Gender & Mean & SD & t - value & df & $\mathbf{p}$ - value \\
\hline \multirow{2}{*}{ Ease of Use } & Male & 20.03 & 3.710 & .115 & \multirow{2}{*}{142} & \multirow{2}{*}{0.798} \\
\cline { 2 - 5 } & Female & 19.96 & 3.452 & & & \\
\hline \multirow{2}{*}{ Trust } & Male & 21.82 & 2.643 & .611 & \multirow{2}{*}{142} & 0.459 \\
\cline { 2 - 5 } & Female & 21.57 & 2.317 & & & 0.303 \\
\hline \multirow{2}{*}{ Usefulness } & Male & 21.43 & 3.085 & $0.588^{\text {NS }}$ & 142 & \\
\cline { 2 - 5 } & Female & 21.16 & 2.417 & & & \\
\hline \multirow{2}{*}{ Security } & Male & 16.84 & 2.464 & -.778 & \multirow{2}{*}{142} & \multirow{2}{*}{0.946} \\
\cline { 2 - 4 } & Female & 17.14 & 2.264 & & & \\
\hline
\end{tabular}

The Correlation analysis has been conducted to identify the mutual relationship between four of the major variables, which leads to mobile app intention to use. The correlations between the adopted variables shown in Table 2.

Table 3 Internal Reliability

\begin{tabular}{|l|c|}
\hline \multicolumn{1}{|c|}{ Factors } & Cronbach's Alpha (CA) \\
\hline Usefulness & 0.82 \\
\hline Ease of Use & 0.803 \\
\hline Trust & 0.814 \\
\hline Security & 0.858 \\
\hline Overall Reliability & 0.902 \\
\hline
\end{tabular}

Reliability of constructs can be measured by Cronbach's alpha (CA). The CA supports internal validity and items consistency. The commonly accepted CA's value of 0.60 and more. Table 3, reveals overall level of CA that is 0.902 and this demonstrates the conducted survey questionnaire is a reliable measurement method. The results show that each individual Likert scale factors has a CA $>0.07$ where data is highly reliable.

Table 4 Correlation coefficients

\begin{tabular}{|c|c|c|c|c|c|}
\hline \multicolumn{2}{|c|}{} & PU & PEOU & TR & SE \\
\hline \multirow{3}{*}{ IU } & R & $.434 * *$ & $.311^{* *}$ & $.544^{* *}$ & $.376^{* *}$ \\
\cline { 2 - 6 } & $\begin{array}{c}\text { Sig. (2- } \\
\text { tailed) }\end{array}$ & .000 & .000 & .000 & .000 \\
\hline
\end{tabular}

Table 4 shows the Pearson correlation coefficient between the variables. The correlation between PU and IU is $(r=.434$, $\mathrm{p}<.05)$ which supports the proposed hypothesis 1 . Hypothesis 2 is supported by the correlation between PEOU and IU $(\mathrm{r}=.311, \mathrm{p}<.05)$. The correlation coefficient between TR and $\mathrm{UI}$ is $(\mathrm{r}=.544, \mathrm{p}<.05)$ that supports hypothesis 3 . The coefficient correlation between SE and IU is $(r=.376, p<0.05)$ which supports hypothesis 4 .

Table 5 Factor loadings of the items

\begin{tabular}{|c|c|c|}
\hline Items & Items' measurement & $\begin{array}{l}\text { Factor } \\
\text { Loading }\end{array}$ \\
\hline \multirow{5}{*}{ Usefulness } & $\begin{array}{l}\text { Perceived Usefulness (PU)-I believe it } \\
\text { enables me to find vaccination details and } \\
\text { history quickly }\end{array}$ & .744 \\
\hline & $\begin{array}{l}\text { Perceived Usefulness (PU)-I believe it } \\
\text { enables me to pay fees in an easily }\end{array}$ & .749 \\
\hline & $\begin{array}{l}\text { Perceived Usefulness (PU)-I believe it } \\
\text { meets my needs }\end{array}$ & .785 \\
\hline & $\begin{array}{l}\text { Perceived Usefulness (PU)-I believe it } \\
\text { helps me to know in advance on next } \\
\text { appointment dates }\end{array}$ & .754 \\
\hline & $\begin{array}{l}\text { Perceived Usefulness (PU)-I believe it } \\
\text { does everything I would expect it to do }\end{array}$ & .783 \\
\hline Security & $\begin{array}{l}\text { Please rate your level of Security } \\
\text { when using the UAE-MOH mServices-I } \\
\text { believe it is financially secure }\end{array}$ & .786 \\
\hline
\end{tabular}




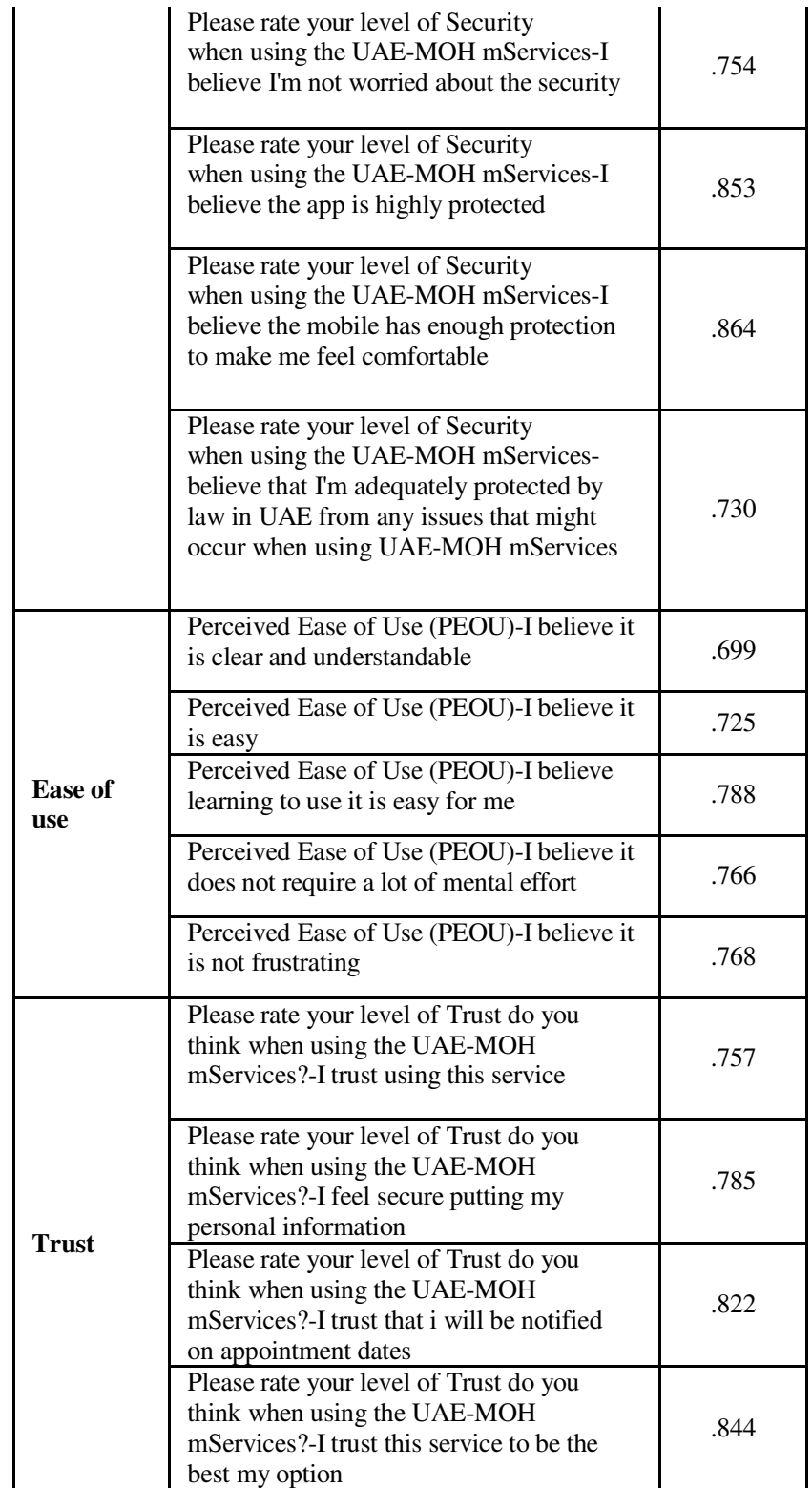

All factor loadings are high (preferably $>.5$ ) on its parent factor with low cross loading $(<.32)$ on the other. Hence, we conclude the convergent validity.

The proposed measurement model considered acceptable with the evidence correlation coefficient, reliability, discriminant and convergent validity for testing hypotheses and validation of the research model. Table 6 shows discriminant validity.

Table 6 Discriminant validity

\begin{tabular}{|l|l|l|l|l|}
\hline & PU & SE & PEOU & TR \\
\hline PU & 0.764 & & & \\
\hline SE & 0.421 & 0.754 & & \\
\hline PEOU & 0.562 & 0.314 & 0.748 & \\
\hline TR & 0.385 & 0.449 & 0.375 & 0.803 \\
\hline
\end{tabular}

The proposed measurement model considered acceptable with the evidence correlation coefficients, reliability, discriminant and convergent validity for testing hypotheses and validation of the research model.

\section{CONCLUSION AND FUTURE WORK}

During the course of this research study, most of the government and non-government hospitals, clinics and private clinics did not have prior knowledge about the MOH's mobile services. We observed that little or no awareness of the use of smart phones among the publics including health professionals, patients and visitors. Lot of efforts have to be done to establish communications outreach to publics and create full awareness of the application of M-Health to this field of healthcare. This study investigated the factors that affects the acceptance of M-Health. The investigation has validated proposed hypotheses and model. PU, PEOU, TR and SE found directly influencing the intention to use M-Health services. In future work, we intend to incorporate more variables and test their applicability as well as increase the sample size of study to provide responses that can be generalized from the sample and compare responses over diverse groups.

\section{REFERENCES}

[1] World Health Organization, "mHealth - New horizons for health through mobile technologies," Global Observatory for eHealth series, Vol. 3, page 6, Available: http://ec.europa.eu/ [Accessed June 20, 2015].

[2] Darrell M. West, "Improving Health Care through Mobile Medical Devices and Sensors," CFTI, 2013 [On-Line]. Available: http://www.brookings.edu [Accessed June 20, 2015]

[3] X.-t. Guo et al., (2012), "Understanding the acceptance of mobile health services: A Service participant's analysis, Management Science and Engineering (ICMSE)," International Conference, pp. 1868 -1873.

[4] Darrell M. West, "Using mobile technology to improve maternal health and fight Ebola: A case study of mobile innovation in Nigeria," CFTI, 2015 [On-Line]. Available: http://www.brookings.edu [Accessed July 1, 2015]

[5] Alenka Brezavšček et al. (2014). Extended Technology Acceptance Model for SPSS Acceptance among Slovenian Students of Social Sciences." Organizacija. [On-Line]. Vol. 47, pp116-127. Available: http://organizacija.fov.uni-mb.si/

[6] Davis, F. (1989), Perceived usefulness, perceived ease of use, and user acceptance of IT. MIS Quarterly 13, 319-340

[7] H. AL-Busaidi. "A model of intention to use mobile government services." PhD. Thesis, Victoria University, Australia, 2012.

[8] Venkatesh, V., Morris, M.G., Davis, G.B. \& Davis, FD. (2003), "User Acceptance of Information Technology: Toward a unified view", MIS Quarterly, Vol. 27, no. 3, pp. 425-78

[9] Taylor, S. \& Todd, P. (1995), "Understanding information technology usage: A Test of Competing models", Information Systems Research, Vol. 6, pp. 144-76

[10] I. Ajzen and M. Fishbein (1980). "Understanding attitudes and predicting social Behavior." Englewood Cliffs, NJ: Prentice-Hall.

[11] I. Ajzen (1991), "The theory of planned behavior", Organizational Behavior and Human Decision Processes, Vol. 50, pp. 179-211

[12] K. Mathieson (1991), "Predicting user intentions: Comparing the technology acceptance Model with the theory of planned behavior," Information Systems Res. 2, 173-191.

[13] A.H.H.M. Mohamed, D. Al-Jumeily, H. Tawfik, L. Norton (2011), MoHTAM: A Technology Acceptance Model for Mobile Health Applications, Developments in E-Systems Engineering (DeSE), IEEE, pp. 13-18.

[14] S.G. Yaseen and S. Zayed, (2010), "Exploring determinants in deploying mobile commerce technology: Amman stock exchange, Information Society (i-Society)", International conference on IEEE, pp. 612-620.

[15] S. Von Watzdorf, et al. (2010), the Influence of Provider Trust on the Acceptance of Mobile Applications: An Empirical Analysis of Two Mobile Emergency Applications, Mobile Business and Ninth Global Mobility Roundtable (ICMBGMR), 9th Int. Conference, pp. 329-336. 
[16] S.G. Yaseen and S. Zayed, (2010), Exploring determinants in deploying mobile commerce technology: Amman stock exchange, Information Society (i-Society), 2010 Int. Conference, pp. 612-620.

[17] Michael Reid. "Integrating Trust and Computer Self-Efficacy with TAM: An Empirical Assessment of Customers' Acceptance of Banking Information Systems (BIS) in Jamaica." Journal of Internet Banking and Commerce, Vol. 12, No. 3, pp. 5-12, Dec. 2008.

[18] U.J. Godwin, (2001), Privacy and security concerns as major barriers for e- commerce: a survey study, Information Management \& Computer Security Vol. 9, pp. 165-174.

[19] Fishbein, M. and Ajzen, I. Belief, Attitude, Intention and Behavior: An Introduction to Theory and Research. Reading, MA: Addison-Wesley, 1975.

[20] Mathieson, K. "Predicting User Intentions: Comparing the Technology Acceptance Model with the Theory of Planned Behavior," Information Systems Research, 2, 1991, pp. 184-189.

[21] Vangie Beal, " IVR - interactive voice response," webopedia.com, May, 2014. [OnLine]. Available: http://www.webopedia.com

[22] Gretchen Gavett, "How Self-Service Kiosks Are Changing Customer Behavior". [OnLine]. Available: https://hbr.org/2015/03/how-selfservice-kiosks-are-changing-customer-behavior [Accessed: June 14, 2015]

[23] Ya-Yueh S. and Kwoting F.," The use of a decomposed theory of planned behavior to Study Internet banking in Taiwan," April 2004. [Online]. Available: http://www.emeraldinsight.com/loi/intr [Accessed: June 2015] 